\title{
Winter activity of a population of greater horseshoe bats
}

\section{Rhinolophus ferrumequinum}

\author{
Kirsty J. Park, Gareth Jones \& Roger D. Ransome \\ School of Biological Sciences, University of Bristol, Woodland Road, Bristol BS8 1UG, \\ U.K.
}

Short title: Winter activity of bats

Key words: Hibernation, torpor, Chiroptera

Address for correspondence: Dr Gareth Jones, School of Biological Sciences, University of Bristol, Woodland Road, Bristol BS8 1UG

Tel (0117) 9287575

Fax (0117) 9257374

e-mail Gareth.Jones@bris.ac.uk 


\section{Summary}

Activity patterns of a greater horseshoe bats Rhinolophus ferrumequinum were investigated at caves in Cheddar (south-west England) during the hibernation season. An ultrasound detector and datalogger were used to monitor and record the number of echolocation calls in a single cave. Activity of $R$. ferrumequinum remained largely nocturnal throughout winter, and the mean time of activity over 24 hours was 88 to 369 minutes (1.47 to 6.15 hours) after sunset. There was an increase in diurnal activity from late May to early June, probably because bats remained active after foraging at dawn towards the end of the hibernation season. Visits to the cave did not increase bat activity. Cave air temperature reflected external climatic temperature, although there was variation in cave temperature and its range within and across caves. Individual $R$. ferrumequinum are usually dispersed in caves in regions where temperature fluctuations correlate with climatic variations in temperature. There was a positive correlation between the number of daily bat passes monitored by the bat detector and datalogger (= daily activity) and cave temperature. Nocturnal activity may sometimes be associated with winter feeding. Neither date nor barometric pressure had a significant effect on daily activity. Activity patterns largely reflected the findings from individual $R$. ferrumequinum studied by telemetry (Park, 1998), in that bat activity increased with cave and climatic temperatures, and the temporal pattern of activity remained consistently nocturnal throughout winter, starting at dusk. 


\section{Contents}

Page

Introduction

3

Methods and materials

6

Results

10

Discussion

14

References

22

\section{Introduction}

\section{Population studies of bat activity}

Many workers investigating bat activity examine activity levels of populations of bats, and do not observe the behaviour of individuals directly. Results from these studies are often then used to make deductions about individual behaviour (e.g. Thomas, 1993).

Ultrasound detectors are often used for assessing bat activity, and broad-band detectors can be used to discriminate between some species (Vaughan, Jones \& Harris, 1997). Simple narrow-band detectors tuned to a single frequency can be used to identify species if only one species echolocates at a given frequency in a particular area (e.g. Nagel \& Nagel, 1997). Alternatively, population estimates of species in hibernacula may enable the investigator to ascertain which species accounts for the majority of data collected (e.g. Thomas, 1993). If activity patterns differ among species, however, it would be difficult to make inferences about the behaviour of any particular species. 
Infra-red light barriers positioned in hibernacula can detect the flight activity of bats during arousals from torpor (Nagel \& Nagel, 1994; Thomas, 1995). Using a photo-electric beamsplitter to trigger a camera and flash, photographs of bats inside caves and mines can be taken. Not only does this technique allow discrimination between those bats leaving and those entering the cave but it may also allow species identification (Daan, 1970; 1973; Lubczyz \& Nagel, 1995).

\section{Bat activity during the hibernation period}

Throughout this paper the hibernation terminology used follows that given by Ransome (1990). Bat activity reaches its lowest levels during mid-winter when the proportion of time spent in torpor is greatest (Daan, 1973; Nagel \& Nagel, 1994; Degn, Andersen \& Baagøe, 1995; Lubczyz \& Nagel, 1995; Thomas, 1995; Nagel \& Nagel, 1997). Ransome (1968; 1971) showed that $R$. ferrumequinum selects lower cave temperatures at this time, and arouses least often. He also produced indirect evidence for successful foraging throughout the hibernation period, whenever external air temperature exceeded $10^{\circ} \mathrm{C}$ and permitted insect flight (Ransome, 1968; 1971). Foraging is the only post-arousal activity in winter which requires arousal to be synchronised with dusk. Dusk is the most favourable time for foraging, since darkness permits flight outside the hibernaculum at a time of highest external air temperatures than during any other period of the night. If successful, foraging leads to prolonged nocturnal activity while food is digested.

Studies have produced conflicting results of the extent to which bat activity remains nocturnal during winter. In a population consisting largely of Myotis daubentonii, less activity occurred during the day than at night throughout winter (Daan, 1973). The pronounced nocturnality, however, that characterises activity patterns in October 
diminishes as the season progresses, before increasing again in late winter (Daan, 1973; Nagel \& Nagel, 1994). Diurnal activity increased in a hibernaculum containing $M$. daubentonii and M. nattereri from 2.4\% in October to 8.7\% in December (Lubczyz \& Nagel, 1995). It is not clear if this result is statistically significant, however, and activity is still very much biased towards nocturnality in December. Thomas (1995) studying Myotis lucifugus and Myotis septentrionalis activity between January and March found no difference in the number of day and night-time flights which were detected by an infra-red beam. During April there was an increase in the proportion of night-time flights. This contrasts with a study using an ultrasound detector to monitor bats at the same site, which found consistently more activity at night than in the day over the winter (Thomas, 1993). Most activity of Rhinolophus hipposideros registered by ultrasound detectors occurred between sunset and sunrise throughout winter (Nagel \& Nagel, 1997). These conflicting results may reflect species and locality differences in the potential for winter foraging, which must be influenced by the severity of the local winter climate, and insect availability.

Studies of population activity that use the methods described above can accumulate considerable data over long time periods. Because the systems are automated they are less time-consuming than, for example, radio-telemetry studies of individual bats. Most importantly, they involve minimal disturbance. Few studies, however, are able to ascertain to what extent the behaviour of a population reflects individual behaviour. In another study (Park, 1998) the thermoregulatory activity patterns and flight behaviour of individual $R$. ferrumequinum over the hibernation season were determined by using temperature-sensitive radio-transmitters. The aim of this study was to describe the activity of a hibernating population of bats in a cave, and to compare these results with those from a radio-telemetry 
study carried out concurrently. This comparison should determine the validity of inferring individual behaviour from population behaviour.

\section{Methods and materials}

The study was carried out during the winters of 1995/6 and 1996/7, in Gough’s Old Cave in Cheddar Gorge (south-west England: Ordnance Survey Grid reference ST468539). This is the main bat hibernaculum in Cheddar Gorge, and is approximately $75 \mathrm{~m}$ long and $20 \mathrm{~m}$ deep (Barrington, 1964). Approximately $20 \mathrm{~m}$ inside this cave is an opening to the entrance of Long Hole, a 255 m passage above Gough’s Old Cave. R. ferrumequinum also sometimes hibernates in two other caves in the Gorge, Canyon Cave and Whitespot which are $45 \mathrm{~m}$ and $55 \mathrm{~m}$ long respectively (Ransome, 1968).

Echolocation calls of $R$. ferrumequinum were monitored and used as a measure of activity. R. ferrumequinum emits constant frequency calls at around $83 \mathrm{kHz}$ (Jones \& Rayner, 1989). An ultrasound detector (Mini-2; Ultra Sound Advice, London, UK), with a bandwidth of \pm $4 \mathrm{kHz}$, was tuned to $83 \mathrm{kHz}$ and each call detected was converted to a 36 ms voltage pulse (square wave) by a Schmitt trigger (custom-built by L. Teagle). The device was not triggered by ultrasound pulses (produced by a GTI ultrasound generator; QMC Instruments, London, UK) similar to those emitted by other echolocating bat species in the area, including $R$. hipposideros, the most common other species hibernating in the caves. $R$. hipposideros emits calls at 109 - 117 kHz (Jones, Gordon \& Nightingale, 1992). The ultrasound detector and Schmitt trigger were powered by a 6 v 10 Ah motorcycle battery. A datalogger (Series 800 8-bit Squirrel logger; Grant Instruments, Cambridge, UK) registered 
the total number of square waves received from the trigger every 10 minutes. A temperature probe (accurate to $0.2^{\circ} \mathrm{C}$ ) was attached to the datalogger, and ambient cave temperature was averaged over 10 minute intervals. This equipment was placed in a sealed plastic box with bags of silica gel to reduce humidity and positioned approximately $20 \mathrm{~m}$ inside the cave from the main entrance (= middle site). Bats leaving and returning to the cave via the main entrance were detected by the ultrasound detector. Bats flying into the cave via a smaller second entrance may not have been detected until they reached their preferred hibernation sites. This second entrance, however, has a horizontal grille with narrow bars protecting it, and it is much less likely to be used than the larger vertical grille with wider spaces, at the main entrance.

The number of echolocation call counts per 10 minute period (referred to as activity in future) and temperature records stored in the datalogger were downloaded onto a laptop computer every seven to 10 days during visits to the cave. Approximately five visits a month were made to Gough’s Old Cave from late October to late May or June during the winters of 1995/6 and 1996/7. Each visit lasted an average of 50 minutes (range 5 - 110 minutes) but the time spent within the main part of the cave was only about 15 minutes, as the data were downloaded by the main entrance, away from the bats. On most visits only one person entered the cave and lights were kept away from the walls and ceilings where the bats were roosting. In this way disturbance was minimised. The bats were, however, disturbed and handled during three daytime surveys carried out every winter in October, January and April. Any data collected within the 24 hour period after these surveys were omitted from activity analyses. The distribution of $R$. ferrumequinum throughout the cave during the study, except on the day of these surveys, was unknown. 
The hibernation season was divided into four winter periods; early winter (mid-October to mid-December), mid-winter (mid-December to mid-February) late winter (mid-February to mid-April) and spring (mid-April to late May). In 1996/7 data were collected until 6 June 1997. All times referred to throughout this study are Greenwich Mean Time.

\section{Temporal distribution of activity}

Activity data were plotted against time of day, and mean daily activity within each 10 minute interval was calculated for each winter period in both 1995/6 and 1996/7. For each winter period, Rayleigh's test for randomness was used to determine whether there was a bias in the time distribution of activity (Batschelet, 1981). Absolute time was used for this circular statistical analysis, not time relative to sunset. Sunset times within each winter period varied by only 50 to 100 minutes, representing angles of 12.5 to $25^{\circ}$ which are sufficiently narrow for any bias towards arousing at sunset to be detected. The time that each echolocation call was recorded was converted to degrees and the mean direction and length of the mean vector $(r)$ for each winter period calculated. Mean direction represents the mean time of activity over 24 hours within each winter period. Mean vector length is a measure of the concentration of data around the mean, ranging from 0 to 1 with increasing concentration. For large sample sizes $z$ is used as the test statistic for Rayleigh's test. This is calculated by $z=n r^{2}$ where $n$ represents the sample size (Batschelet, 1981). 


\section{Disturbance}

In order to ascertain whether bats were disturbed by visits to the cave, we compared the amount of activity occurring between the end of a cave visit and sunset time with the amount of activity occurring during the same time period on the previous day. No unauthorised entrance to the cave was possible as both entrances were grilled.

\section{Cave temperatures}

Ambient cave temperature (accurate to $0.2^{\circ} \mathrm{C}$ ) was also monitored by the main entrance (= front) and approximately $30 \mathrm{~m}$ inside the cave, from the main entrance (= back) using two temperature probes (Tinytalk; Orion Components, Chichester, UK). Temperature probes were positioned at similar heights (1-2 m) throughout Gough’s Old Cave to minimise any possible effect of a height-dependent temperature gradient. Each temperature probe was programmed to take a reading every 72 minutes, and data were downloaded every three months. Another temperature probe was positioned at a height of $2 \mathrm{~m}$ about $20 \mathrm{~m}$ inside Canyon Cave (length ca. $45 \mathrm{~m}$ ), close to where the bats roosted. Canyon Cave is another cave with dynamic air-flow, and most bats that hibernate there roost at 3-4 m height. Climatic temperature (accurate to $0.1^{\circ} \mathrm{C}$ ) was measured at sunset each night outside Gough’s Old Cave and Canyon Cave by using a digital thermometer. Sunset was ascertained by using Whitaker’s Almanac (Marsden, 1995 - 1997). The relationship between cave temperature (at the front, middle and back of Gough’s Old Cave and from Canyon Cave) and climatic temperature close to sunset was determined using linear regression analysis.

\section{Barometric pressure}


Daily barometric pressure readings (mb) were obtained from The Meteorological Office (Bristol Weather Centre, approximately 20 km north-east of Cheddar Gorge) for November 1995 to May 1996. Daily pressure readings taken around sunset were used and these were corrected to sea level measurements.

Activity levels throughout winter

The relationship between total daily activity and mean daily cave temperature (from the middle of Gough's Old Cave) was determined by using Spearman rank correlations as data could not be normalised. An analysis of covariance (ANCOVA) was used to investigate the effects of winter period (factor) and barometric pressure (covariate) on activity for the winter of 1995/6. The square roots of total daily activity data were used to achieve normality.

Comparison with individual bats

The amount of total daily activity was compared to the proportion of radio-tagged bats arousing each night (Park, 1998).

\section{Results}

\section{Population size}

The total number of $R$. ferrumequinum found in Cheddar Gorge during each of the three surveys in the winters of 1995/6 and 1996/7 varied between 48 - 67 bats, with 8 - 65 bats frequenting Gough’s Old Cave (Table 1). 
Table 1

\section{Temporal distribution of activity}

Most activity occurred between sunset and sunrise; only $12.7 \%$ of activity took place during the day (Fig. 1). This nocturnal pattern was consistent throughout winter. During the spring period of 1997, when data were added from late May to 6 June, the temporal distribution of activity changed greatly (Fig. 2). A larger proportion (31.6 \%) of the activity recorded took place during the day although the two main peaks of activity were at $2100 \mathrm{~h}$ and just before $0400 \mathrm{~h}$ (i.e. approximately an hour after sunset and an hour before sunrise).

Fig. 1

Fig. 2

All winter periods showed a non-random temporal distribution of activity (Table 2). Mean time of activity varied from $1946 \mathrm{~h}$ to $2226 \mathrm{~h}$, a range of only 160 minutes. Changes in the mean time of activity did not appear to correspond to changes of sunset time.

Table 2

\section{Disturbance}

There was no significant difference in the amount of activity occurring between the end of a cave visit and sunset time compared with the amount of activity occurring during the same time period on the previous day (Wilcoxon signed rank test $W_{48}=-26.0, \mathrm{NS}$ ). The median 
amount of activity before a cave visit $=0.0$ (interquartile range $0.0-2.5$ ), and after a visit $=$ $0.0(0.0-1.5)$

\section{Cave temperatures}

There was a significant positive relationship between climatic temperature and cave temperature at sunset throughout Gough’s Old Cave and in Canyon Cave (Linear Regression for front, middle and back of Gough's Old Cave and Canyon Cave: $F_{1,200}=$ 753.3, $p<0.0001 ; F_{1,130}=357.1, p<0.0001 ; F_{1,134}=127.7, p<0.0001 ; F_{1,110}=66.4, p<$ 0.0001 respectively). All the regressions were highly significant although the percentage of variation in cave temperature that is due to variation in climatic temperature $\left(r^{2}\right)$ was higher at the front and in the middle of Gough's Old Cave than at the back, and in Canyon Cave where temperatures are more stable (Table 3). Cave temperatures from the middle of Gough’s Old Cave are shown in Fig. 3.

Table 3

On average, over the entire winter, the front of Gough's Old Cave was significantly colder and more variable than the back of Gough's Old Cave or Canyon Cave in the winter of 1995/6 and 1996/7 (1996/7: Post-hoc test Dunn’s Method $Q=40.5, p<0.05 ; Q=18.3, p<$ 0.05 respectively; Table 3). The back of Gough’s Old Cave and Canyon Cave both had fairly stable temperature regimes, but Canyon Cave was on average, $1^{\circ} \mathrm{C}$ colder than the back of Gough's Old Cave during the winter of 1996/7 $(Q=22.2, p<0.05)$.

Activity levels throughout winter 
Fig. 3

During both winters, total activity recorded each day was generally under 400 calls although occasionally high levels of activity were recorded for one or two days. The amount of activity recorded between late May and early June 1997 was very high (Fig. 3b).

During both winters there was a positive correlation between daily activity and cave temperature over the period between late October and May/June (Spearman rank correlation coefficient $r_{s} 188=0.15, p<0.05 ; r_{s} 203=0.30, p<0.001$ for $1995 / 6$ and 1996/7 respectively). The coefficient for these correlations, however, was low. Fig. 4 shows that low activity levels could occur whatever the cave temperature, but high levels only occurred at relatively high cave temperatures.

Fig. 4

Data from each year were split into separate winter periods in an attempt to control for nontemperature-dependent seasonal effects. Only in spring 1997 did daily activity increase with an increase in cave temperature ( $r=0.72, p<0.001, n=48$ ). Cave temperatures (from the middle of Gough’s Old Cave) were significantly higher in spring 1997 than in spring 1996 (Mann-Whitney $48,34 T=908.5, p<0.0001$ ).

Overall, cave temperature and daily activity were positively correlated but, with the exception of the warm spring in 1997, there was no correlation between cave temperature and daily activity within each winter period, and little difference between winter periods. 
In the ANCOVA to analyse the effect of winter period and barometric pressure on activity, the interaction term between winter period and barometric pressure was not significant so was removed from the model and the ANCOVA repeated. There was no effect of winter period or barometric pressure on the square roots of daily activity of $R$. ferrumequinum (winter period $F_{3,183}=2.06$, NS; barometric pressure $F_{1,183}=2.42$, NS).

\section{Comparison with individual bats}

There was a positive correlation between the total daily activity of the population of $R$. ferrumequinum recorded in this study and the proportion of radio-tagged individuals that aroused each night (Park, 1998) (Spearman rank correlation coefficient $r_{s 215}=0.15, p<$ $0.05)$.

\section{Discussion}

The amount of activity recorded by an ultrasound datalogger at a particular location in a specific cave will potentially be influenced by many variables. These include the number of bats present, their arousal frequency, the duration of their post-arousal activity and the entry of active bats from other caves. In addition, the position and sensitivity of the bat detector will influence how much activity is recorded. The system used here probably detected bats over about $10 \mathrm{~m}$, and was located in a position which monitored all bats exiting, and most entering the study cave. It could not record calls from bats that had left to forage outside the cave, or those which may have clustered in high rifts beyond the range of the bat detector, after foraging. Hence the activity levels must be regarded as minima. 


\section{Temporal distribution of activity}

The activity of $R$. ferrumequinum remained nocturnal throughout winter, with the mean time over 24 hours from 88 to 369 mins after sunset. The average arousal duration of radiotagged $R$. ferrumequinum during winter was 260 mins, but ranged from 37 mins to 54.4 hours (Park, 1998). Hence the variability of arousal duration among individuals accounts for some of the changes in mean activity time, and explains why changes in activity times do not correspond precisely with changes in sunset time.

Thomas (1993) found that, although there was more activity of Myotis lucifugus and Myotis septentrionalis at night than in the day, there was little concentration around any one time. A laboratory study of Eptesicus fuscus showed that individuals aroused for approximately 90 minutes (Twente \& Twente, 1987), so Thomas (1993) predicted that if arousals occurred at dusk, the spread of activity throughout the night would be minimal. Post-arousal activity durations obtained in laboratory studies, however, should be treated with caution, as conditions in the laboratory do not reflect those in the field, and the bats in these studies were unable to fly after arousals as they do in the wild. In addition to this, activity durations of E. fuscus may differ from those of M. lucifugus and M. septentrionalis. Thomas (1993) suggested that arousal time becomes random when bats lose 'zeitgebers' (synchronising factors) in winter. This study shows that this does not happen in $R$. ferrumequinum. This may be because either daily external temperature fluctuations, and/or their frequent arousals followed by occasional foraging success, permit synchronisation of their biological clocks with dusk. Griffin \& Welsh (1937) showed that the arousal rhythm of bats could be entrained by feeding. 
There was an increase in diurnal activity from late May to early June as bats spent less time in torpor towards the end of the hibernation season. This probably occurs due to the increasingly regular occurrence of successful foraging at dawn. Time lapse video recordings show most mid-winter foraging occurs around dusk, but as external temperature rises in spring, dawn foraging starts (R. D. Ransome, unpublished). Any successful foraging bout requires an extended period of thermoregulatory activity whilst food is being digested and the bulk of the faeces egested. This can take from six to 12 hours in $R$. ferrumequinum (Ransome, 1978) but may be much shorter in other species.

If only dusk foraging occurs, $R$. ferrumequinum activity is predicted to be entirely nocturnal. If both dusk and dawn foraging is successful, activity may last for 24 hours of the day, and for several days continuously in mild spells. While this thermoregulatory activity is happening, bats tend to cluster together in a suitable vertical rift where they can build up a warm microclimate for economical digestion. This behaviour leads to accumulations of faecal pellets at any time of the winter in temperate climates (Ransome, 1968). In the very mild weather in February 1998 faecal dry mass levels per bat per day at a maternity site in Gloucestershire exceeded those typical of May (R.D. Ransome, unpublished).

Other studies, in which activity periods were found to be more or less random in midwinter (Daan, 1973; Thomas, 1995), show an increasing nocturnal tendency in late winter and early spring. However, these studies did not continue until May. Differences among studies may be explained by the onset of dusk foraging in spring following an absence of mid-winter foraging under severe continental climates, and bats leaving the hibernacula for other roosts as soon as dawn foraging begins. 


\section{Disturbance}

Laboratory studies of torpid vespertilionid bats suggest that they do not arouse in response to non-tactile stimulation such as light, sound and small temperature fluctuations (Speakman, Webb \& Racey, 1991). In contrast, Thomas (1995) studying a natural population of two Myotis species provided evidence that non-tactile disturbance did provoke arousals. We found no evidence of increased activity after visits to Gough's Old Cave. The Myotis bats in Thomas' study (1995) were found at much higher densities than the bats in ours, and in close contact. Since these Myotis bats aroused at random times in winter (Thomas, 1993), some bats would always have been close to their arousal time, whatever time the mine was visited. If these bats were provoked to arouse, they may have disturbed others in a 'cascade' effect as they left their group. In addition, it should be stressed that we attempted to minimise the disturbance to the bats in this study whereas Thomas (1995) was specifically investigating the effects of non-tactile stimulation, so the bats in his study may have been subjected to higher levels of disturbance.

\section{Cave temperatures}

Cave temperature in this study strongly reflected external (climatic) temperature. Gough's Old Cave and Canyon Cave are the main hibernacula used by bats in Cheddar Gorge, hence most bats roosting in the open in these caves could almost certainly detect climatic temperature changes from fluctuations in air temperature at their roosting position. Bats that roost further underground in large cave systems where the air temperature is virtually constant are not able to do this (e.g. Paige, 1995). 
The temperature regimes within different parts of the cave, however, differed. At the front of Gough's Old Cave, air temperature was on average, $2.2-2.6^{\circ} \mathrm{C}$ lower and fluctuated far more than at the back of Gough’s Old Cave and Canyon Cave which had more stable temperature regimes. Bats often form clusters in Canyon Cave during cold weather but move near the entrances of Gough's Old and Long Hole Caves when external temperature increases, perhaps to evaluate feeding conditions better (R.D. Ransome, unpublished). $R$. ferrumequinum prefers the more stable temperature regime of Canyon Cave when conditions for feeding are poor (Ransome, 1968: Gough’s Old = Cave C; Canyon Cave = Cave E, and Whitespot = Cave G). Individuals of this species are rarely found at the back of Gough’s Old Cave which has a similarly stable temperature regime but was, on average, $1^{\circ} \mathrm{C}$ warmer than Canyon Cave. Most of the cave temperatures reported here fall within the range of temperatures $\left(3.0-13.0^{\circ} \mathrm{C}\right)$ at which $R$. ferrumequinum has been recorded torpid in other hibernacula (Ransome, 1968; 1971; Webb, Speakman \& Racey, 1996).

\section{Activity throughout winter}

In this study there was no marked reduction of activity as winter progressed, although recordings did not begin until the end of October and activity may have been higher earlier in the month. Activity of Rhinolophus hipposideros within hibernacula was found to increase at the end of winter, during April and May (Nagel and Nagel, 1997). An increase in activity during these months was not observed in the cold spring of 1996 in this study. However, activity increased in late May and early June in 1997, when temperatures were warm. Ransome (1971) showed that $R$. ferrumequinum can hibernate until the end of May, later than is usually reported for temperate bats at similar latitudes. His findings are confirmed by observation of radio-tagged bats that remained in torpor for up to six days continuously during late May (Park, 1998). 
Overall, there was a positive correlation between daily activity level and cave temperature each winter, but this was primarily due to the influence of activity records from mid-April 1997 onwards. Cave temperatures were significantly higher in 1997 than in 1996 during this period. This suggests that activity only relates to cave temperature during warm spring weather conditions. Arousal frequency of $R$. ferrumequinum increases with an increase in climatic temperature, but the duration of post-arousal activity is largely unaffected until climatic temperatures reach $10^{\circ} \mathrm{C}$ or above (Park, 1998). Since this is the temperature above which significant numbers of insects are likely to fly (Ransome, 1968; Rydell, 1989; Jones et al., 1995), it suggests that the activity duration extension relates to foraging. However, below $10{ }^{\circ} \mathrm{C}$ activity still occurs after arousals, which is probably unrelated to foraging.

Cave air temperature does not influence winter flight activity in Myotis myotis, but activity increases with a reduction in barometric pressure (Nagel \& Nagel, 1994). In this study, the amount of daily activity was not related to either cave temperature in most winter periods or to barometric pressure.

\section{Activity patterns in populations of hibernating bats}

The activity behaviour of bats during the hibernation season will be partly determined by the species of bat and the climatic conditions to which individuals are exposed. For example, $M$. lucifugus roosting in hibernacula in Canada during winter is less likely to be able to forage successfully after arousing than $R$. ferrumequinum in Britain due to the severity of Canadian winters and the lack of available insects (D.W. Thomas, pers. comm.). There seems to be little adaptive function in synchronising arousals with dusk in bats when insects are scarce or absent. 
Random diurnal activity patterns suggest that a free-running state operates, and imply therefore that foraging is not cost-effective. Activity starting at dusk, as we have shown, indicates that foraging at dusk is frequently successful enough for arousal to be synchronized by a 'zeitgeber' such as daily cave temperature fluctuations. No other suggested activities during post-arousal thermoregulation require a bat to arouse at dusk. Bats can drink, excrete, mate or sleep at any time of the 24 hour period.

This is one of the first studies to ascertain the extent to which the activity of a bat population reflects individual activity patterns. Total daily activity was positively correlated with the proportion of radio-tagged bats arousing each night (Park, 1998), and the temporal activity patterns found in this study reflected the findings from individual $R$. ferrumequinum (Park, 1998). Population studies investigating bat activity patterns usually involve less disturbance than those following individuals, and provided the limitations of such methods are recognised, they can be used to make some inferences about bat hibernation behaviour.

\section{Acknowledgements}

We thank to Hugh Cornwell, Manager of Cheddar Showcaves, who allowed us access to Gough’s Old Cave. We also gratefully acknowledge help from Colin Hurst at Bristol Weather Centre (The Meteorological Office) who provided barometric pressure readings, and Linda Teagle who designed the Schmitt trigger. Alistair McInnes, Will Strange, Lucy Clark and Claire Swinyard helped with data collection. Thanks also to John Altringham 
(University of Leeds) for the loan of some Tinytalk temperature probes, and for his comments on the manuscript. Peter Webb made several useful suggestions for changes to the original manuscript. Work presented in this paper was carried out under licence from English Nature. K.J.P. was funded by a Natural Environmental Research Council studentship, and G.J. by a Royal Society University Research Fellowship. 


\section{References}

Barrington, N. (1964). The Caves of Mendip. Lancaster: Dalesman Publishing Co.

Batschelet, E. (1981). Circular Statistics in Biology. New York: Academic Press.

Daan, S. (1970). Photographic recording of natural activity in hibernating bats. Bijdr. Dierk. 40: 13 - 16.

Daan, S. (1973). Activity during natural hibernation in three species of vespertilionid bats. Neth. J. Zoology 23: 1 - 71.

Degn, H.J., Andersen, B.B. \& Baagøe, H. (1995). Automatic registration of bat activity through the year at Mønsted limestone mine, Denmark. Z. Säugetierkunde 60: 129 - 135.

Griffin, D.R. \& Welsh, J.H. (1937). Activity rhythms in bats under constant external conditions. J. Mammal. 21: 306-315.

Jones, G. \& Rayner, J.M.V. (1989). Foraging behavior and echolocation of wild horseshoe bats Rhinolophus ferrumequinum and R. hipposideros (Chiroptera, Rhinolophidae). Behav. Ecol. Sociobiol. 25: 183-191.

Jones, G., Duvergé, P.L. \& Ransome, R.D. (1995). Conservation biology of an endangered species: field studies of greater horseshoe bats. Symposia of the Zoological Society of London, 67, 309-324.

Jones, G., Gordon, T. \& Nightingale, J. (1992). Sex and age differences in the echolocation calls of the lesser horseshoe bat, Rhinolophus hipposideros. Mammalia 56: 189-193.

Lubczyz, P. \& Nagel, A. (1995). Aktivität von fledermäusen an einem winterquartier im Landkreis Lüchow-Dannenberg (Niedersachsen, BRD) im winterhalbjahr 1993/94. Ornithol. Beob. 92: 339 - 344.

Marsden, H. (1995). Whitaker's Almanack. London: J. Whitaker \& Sons Ltd. 
Marsden, H. (1996). Whitaker’s Almanack. London: J. Whitaker \& Sons Ltd.

Marsden, H. (1997). Whitaker’s Almanack. London: J. Whitaker \& Sons Ltd.

Nagel, A. \& Nagel, R. (1994). Activity of hibernating bats in their natural habitat recorded by automatic data logging. Bat Research News 35: 37.

Nagel, A. \& Nagel, R. (1997). Utilization of an underground roost by the lesser horseshoe bat (Rhinolophus hipposideros). In: Zur Situation der Hufeisennasen in Europa: 97 108. Arbeitskreises Fledermäuse Sachsen-Anhalt e.V. (Ed.). Berlin: IFA Verlag GmbH. Paige, K.N. (1995). Bats and barometric pressure: conserving limited energy and tracking insects from the roost. Funct. Ecol. 9: 463 - 467.

Park, K.J. (1998). Roosting Ecology and Behaviour of Four Temperate Species of Bat. PhD thesis, University of Bristol.

Ransome, R. D. (1968). The distribution of the greater horseshoe bat, Rhinolophus ferrumequinum, during hibernation, in relation to environmental factors. J. Zool. (Lond.) 154: 77 - 112.

Ransome, R.D. (1971). The effect of ambient temperature on the arousal frequency of the hibernating greater horseshoe bat, Rhinolophus ferrumequinum, in relation to site selection and the hibernation state. J. Zool. (Lond.) 164: 353 - 371.

Ransome, R.D. (1978). Daily activity patterns of the Greater horseshoe bat, Rhinolophus ferrumequinum, from April to September. In Proceedings of the Fourth International Bat Research Conference: 71-82. Olembo, R.J., Castelino, J.B. and Mutere, F.A. (Eds.), Nairobi: Kenya National Academy for Advancement of Arts and Science, Kenya Literature Bureau.

Ransome, R.D. (1990). The Natural History of Hibernating Bats. London: Christopher Helm. 
Rydell, J. (1989). Feeding activity of the northern bat Eptesicus nilssoni during pregnancy and lactation. Oecologia 80: 562 - 565.

Speakman, J.R., Webb, P.I. \& Racey, P.A. (1991). Effects of disturbance on the energy expenditure of hibernating bats. J. Appl. Ecology 28: 1087 - 1104.

Thomas, D.W. (1993). Lack of evidence for a biological alarm clock in bats (Myotis spp.) hibernating under natural conditions. Can. J. Zool. 71: 1 - 3.

Thomas, D.W. (1995). Hibernating bats are sensitive to non-tactile human disturbance. $J$. Mammal. 76: 940 - 946.

Twente, J.W. \& Twente, J.A. (1987). Biological alarm clock arouses hibernating big brown bats, Eptesicus fuscus. Can. J. Zool. 65: 1668 - 1674.

Vaughan, N., Jones, G. \& Harris, S. (1997). Habitat use by bats (Chiroptera) assessed by means of a broad-band acoustic method. J. Appl. Ecology 34: 716 - 730.

Webb, P.I., Speakman, J.R. \& Racey, P.A. (1996). How hot is a hibernaculum? A review of the temperatures at which bats hibernate. Can. J. Zool. 74: 761 - 765. 
Table 1 The number of $R$. ferrumequinum found in Gough's Old Cave (including Long Hole), Canyon Cave and Whitespot.

\begin{tabular}{lllll}
\hline Date & Gough’s Old Cave & Canyon & Whitespot & Total bats \\
\hline 28 October 1995 & 65 & 1 & 1 & 67 \\
20 January 1996 & 8 & 53 & 1 & 62 \\
06 April 1996 & 10 & 37 & 6 & 53 \\
26 October 1996 & 52 & 14 & 0 & 66 \\
18 January 1997 & 32 & 5 & 11 & 48 \\
05 April 1997 & 28 & 24 & 2 & 54 \\
\hline
\end{tabular}


Table 2 Results of Rayleigh's test for randomness on activity times for each winter period during the winters of 1995/6 and 1996/7. Mean time of activity and sunset time within each winter period are given, $z=$ test statistic, $n=$ total number of echolocation calls recorded. Spring (to late May) 1997 includes activity recorded from mid-April to late May (see Fig. 1(d)). Spring (to early June) 1997 includes activity recorded from mid-April to early June (see Fig. 2).

\begin{tabular}{lllllll}
\hline Winter period & $\begin{array}{l}\text { Mean time of } \\
\text { activity (hours) }\end{array}$ & $\begin{array}{l}\text { Mean sunset } \\
\text { time (hours) }\end{array}$ & $\begin{array}{l}\text { Mean vector } \\
\text { length }(r)\end{array}$ & $z$ & $p$ & $n$ \\
\hline Winter 1995/6: & & & & & & \\
\hline early winter & 2115 & 1617 & 0.65 & 3310 & $<0.0001$ & 7834 \\
mid-winter & 1946 & 1637 & 0.68 & 2523 & $<0.0001$ & 5457 \\
late winter & 2002 & 1822 & 0.71 & 2868 & $<0.0001$ & 5689 \\
spring & 2135 & 1941 & 0.74 & 2254 & $<0.0001$ & 4117 \\
\hline Winter 1996/7: & & & & & \\
\hline early winter & 2226 & 1617 & 0.87 & 5107 & $<0.0001$ & 6747 \\
mid-winter & 2050 & 1637 & 0.69 & 1537 & $<0.0001$ & 3229 \\
late winter & 2110 & 1822 & 0.74 & 2592 & $<0.0001$ & 4733 \\
spring (to late May) & 2216 & 1941 & 0.54 & 5990 & $<0.0001$ & 4378 \\
spring (to early June) & 2120 & 1952 & 0.41 & 1276 & $<0.0001$ & 35636 \\
\hline
\end{tabular}


Table 3 Median cave temperatures and inter-quartile ranges (25\% and $75 \%$ ) for the front and back of Gough’s Old Cave and for Canyon Cave. Temperatures for Canyon Cave during the winter of 1995/6 were only monitored from January 1996 and are not included in this table. $n=$ number of temperature recordings.

\begin{tabular}{llll}
\hline Winter & Median temperature $(25 \%-75 \%)$ & $n$ & Test \\
\hline 1995/6: & & & Mann-Whitney \\
front Gough's Old Cave & $4.9(3.0-7.5)$ & 2738 & $T=5513573$ \\
back Gough's Old Cave & $7.5(7.2-9.0)$ & 3137 & $p<0.0001$ \\
\hline 1996/7: & & 3208 & Kruskal-Wallis \\
front Gough's Old Cave & $6.0(3.7-7.9)$ & 3208 & $p<0.0001$ \\
back Gough's Old Cave & $8.2(7.2-8.6)$ & 3208 & \\
Canyon Cave & $7.2(6.0-7.9)$ & & \\
\hline
\end{tabular}




\section{Figure legends}

Fig. 1 Temporal distribution of mean daily activity over a 24 hour day during the winters of 1995/6 and 1996/7 combined. Each column represents a ten-minute interval. (a) = early winter, $(\mathrm{b})=$ mid-winter, $(\mathrm{c})=$ late winter, $(\mathrm{d})=$ spring (mid-April to late May). The black bars under the $x$-axis indicate the longest period between sunset and sunrise within each winter period

Fig. 2 Temporal distribution of mean daily activity over a 24 hour day from mid-April to early June 1997. Each column represents a ten-minute interval. The black bar under the $x$-axis indicates the longest period between sunset and sunrise over these dates.

Fig. 3 Total daily activity (bars) and average daily cave temperature (lines) from (a) November to late May during the winter of 1995/6, and (b) November to early June during the winter of 1996/7. Each activity bar represents a day. Arrows indicate the date of surveys in October, January and April each winter. In the winter of 1995/6 bats were disturbed twice in January for radio-tagging. Data from these days and the subsequent 24 hours have been omitted. The black bars under the x-axis represent periods of time when no data were collected due to equipment failure.

Fig. 4 The relationship between total daily activity and average daily cave temperature. Data from two years were combined. 

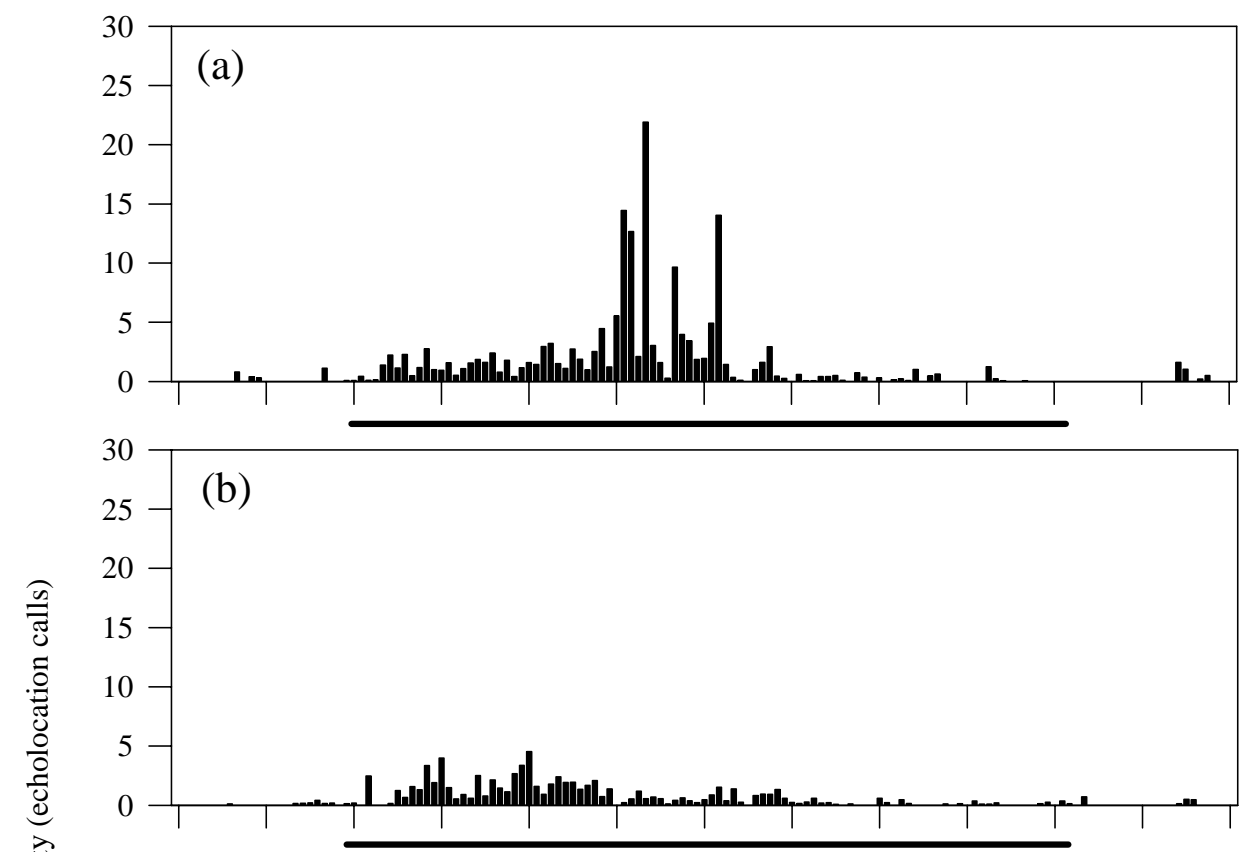

疍
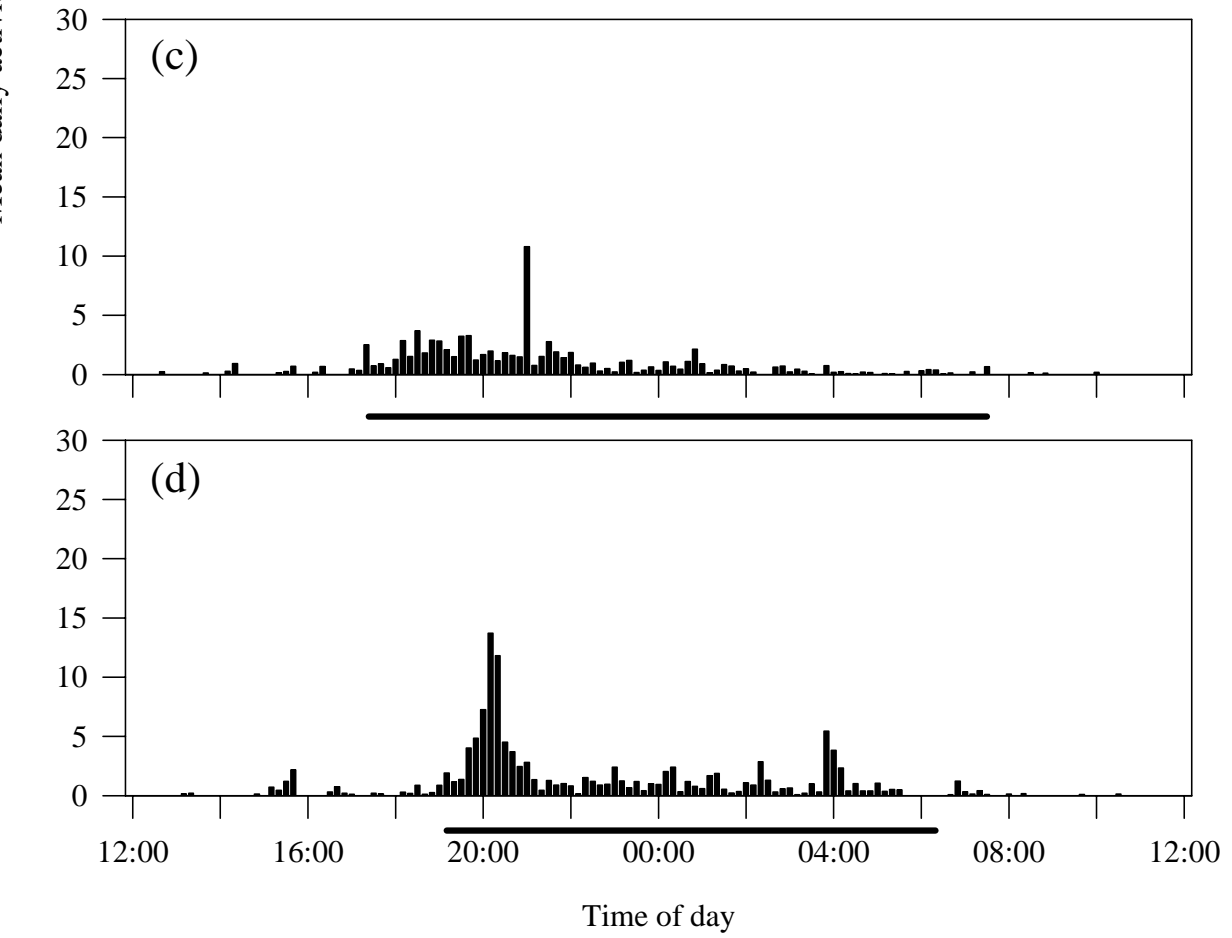

Fig. 1 


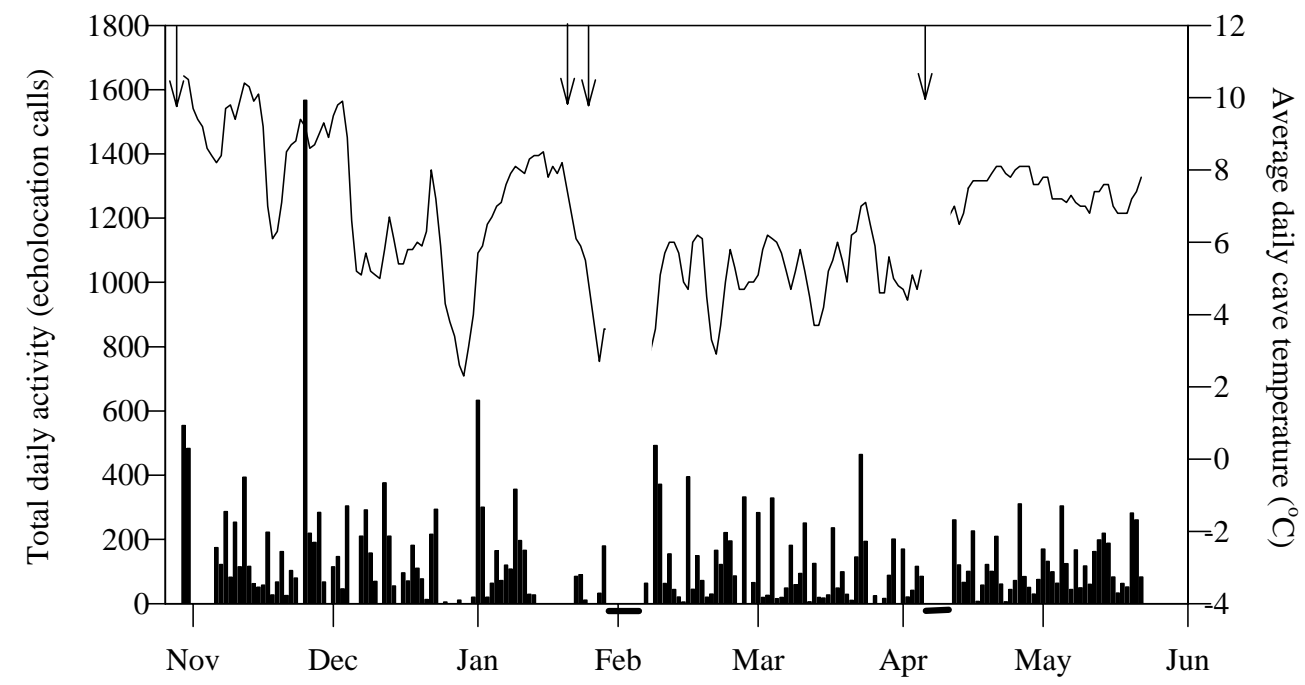

Fig 3a

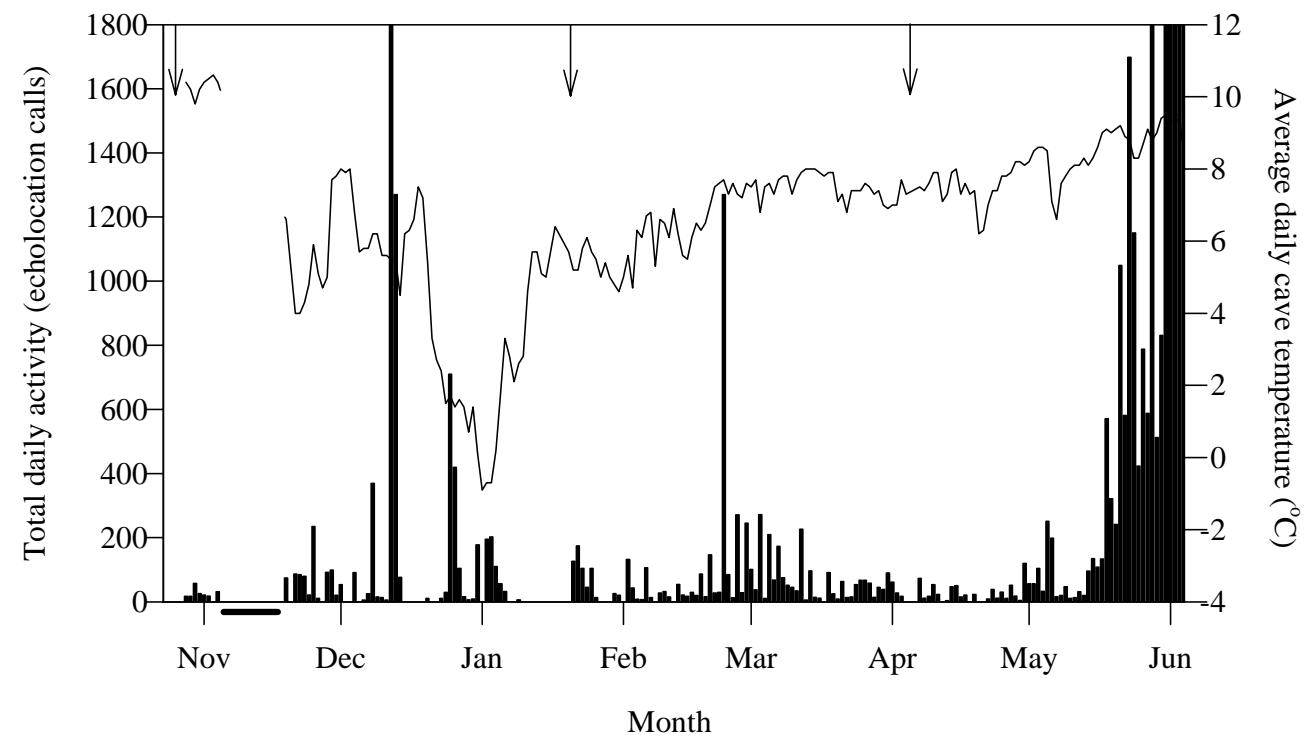

Fig. 3b 


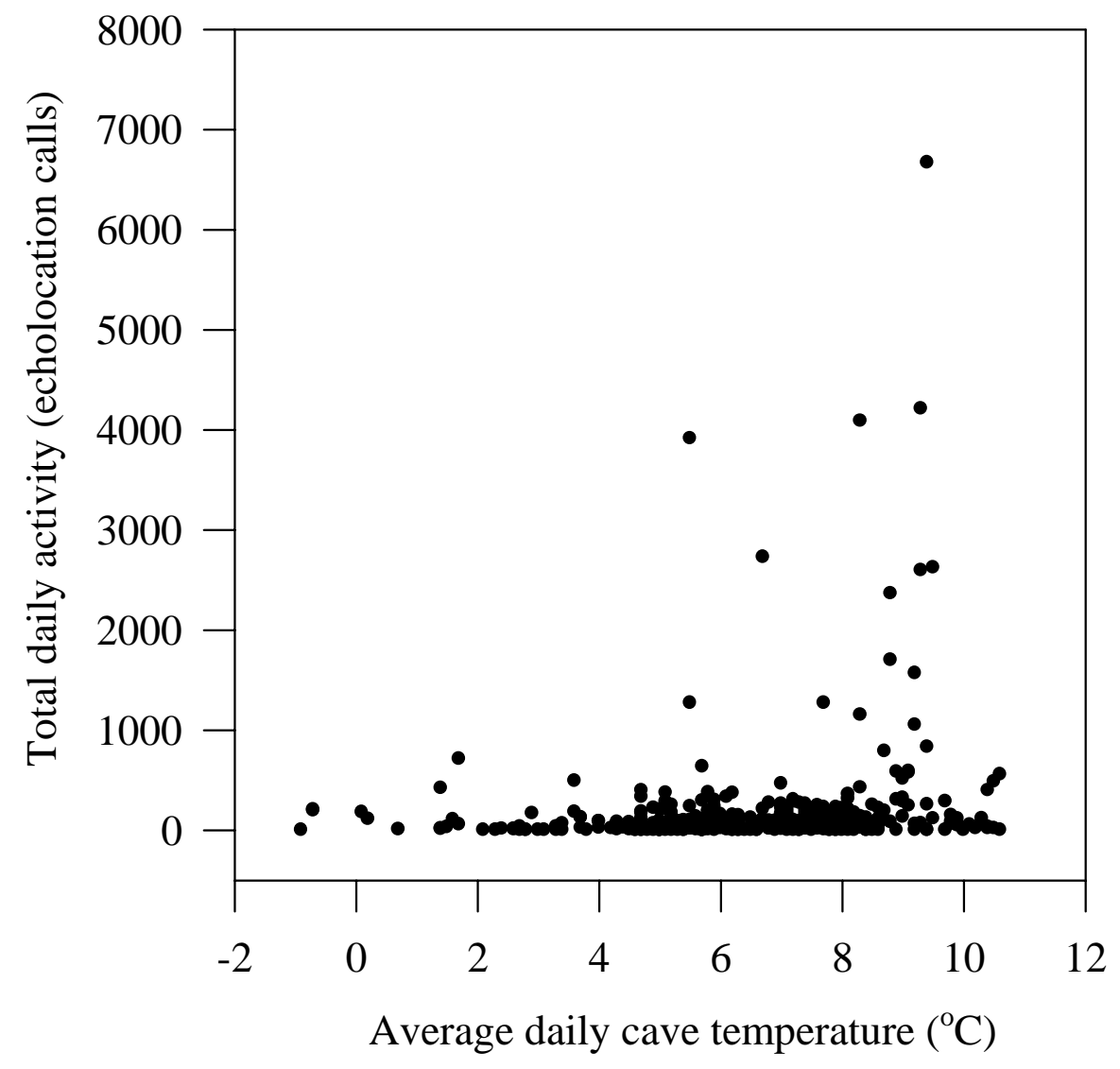

Fig. 4 